\title{
Breve panorama acerca dos estudos feministas
}

\author{
Feminismos Plurais
}

ROCHA, Marcos Antonio Monte

Fortaleza: Expressão Gráfica e Editora, 2016. 158p. [Coleção Gênero, Cultura e Mudança]

O primeiro volume da coleção Gênero, Cultura e Mudanças, Feminismos Plurais, reúne textos apresentados durante o Seminário Internacional Gênero, Cultura e Mudança, inaugurando a primeira das quatro publicações previstas para esta coleção. Esta obra é resultado de uma ação integrada a projetos que visam promover a equidade de gênero e de afirmação da diversidade sexual, tais como: Curta o Gênero, evento promovido pela Fábrica de Imagens (ações educativas em cidadania e gênero através do seu Ponto de Cultura Outros Olhares - equidade e diversidade) e do Cacto (Centro de Referência em Cultura, Arte, Comunicação e Novas Tecnologias para a Promoção dos Direitos Humanos, da Equidade de Gênero e da Diversidade Sexual).

O organizador da coleção, Marcos Antonio Monte Rocha, possui graduação em Psicologia pela Universidade Federal do Ceará, é fundador e editor da ONG Fábrica de Imagens além de possuir atuação proeminente em diversos projetos que relacionam os estudos de gênero.

O volume conta com oito textos que percorrem diferentes perspectivas feministas apresentados no decorrer do Seminário realizado em abril de 2015. O primeiro capítulo, intitulado "Feminismos, artes de viver e invenções da subjetividade", de Margareth Rago, busca apresentar um panorama acerca do uso - e da importância - das teorizações propostas por Michel Foucault para se pensar as subjetividades, a liberdade e o corpo em meio às relações de poder. Ao pensar o cuidado de si, de acordo com Foucault, Rago reflete acerca da importância de os feminismos transnacionais pensarem como formar jovens nas perspectivas feministas e questiona como fazer para que não recaiam na arrogância dos discursos neoliberais que produzem um "indivíduo atomizado, narcisista, voltado para o próprio umbigo, convicto de suas verdades?" (RAGO, 2016, p. 21).

No capítulo seguinte, María Luisa Femenías, em "Esbozo del feminismo en América Latina" discute sobre feminismo, gênero e problemas sexo-gênero na América Latina visando três entrecruzamentos: a fronteira, os entrecruzamentos etnicorraciais e a violência. Ao traçar 
um mapa conceitual que, de antemão admite ser incompleto, apresenta as categorias das quais parte, por meio de uma explanação metodológica e teórica. Categorias como "política de localização", citando Adrianne Rich, e "saberes situados", de Donna Haraway, auxiliaram-na a refletir acerca dos entrecruzamentos entre mestiçagem, religiosidade e diversidade cultural, possibilitando (de)mostrar as formas como as mulheres atendem às teorias e às práticas com forte compromisso social (FEMENÍAS, 2016, p. 27). Nesse sentido, Femenías aponta para a importância da revisão crítica feminista e para as contribuições de Gloria Anzaldúa, Ochy Curiel, Pilar Calviero, Mariza Ruiz, entre outras autoras da teoria decolonial latino-americana que adotam uma atitude cautelosamente crítica ao utilizar as noções de "diferença colonial", "sistema-mundo-moderno-colonial" e "colonialidade".

O terceiro capítulo, intitulado "Ondas mitos e contradições: feminismo em tempos de ditaduras no Cone Sul", de autoria de Cristina Scheibe Wolff, Cíntia Lima Crescêncio e Joana Maria Pedro, apresenta resultados de um amplo projeto de pesquisa envolvendo diversas pesquisadoras e pesquisadores do Cone Sul e discutem os marcos fundacionais do feminismo e suas ondas. Abordar o feminismo como discurso, acontecimento, contribui no afastamento do caráter de invenção que conta com autoria e data, relacionando-o à emergência das demandas sociais e como o discurso se constrói baseado nisso. Ao questionar o marco fundador de $1975 \mathrm{com}$ o Ano da Mulher promulgado pela ONU, as autoras possibilitam lançar diferentes olhares ao humanizar e visibilizar diferentes lutas de mulheres que muito antes desse "olhar institucional" estavam se organizando e enfrentando o sexismo e machismo existentes tanto nas direitas quanto nas esquerdas do Cone Sul.

Buscando aliar aspectos teóricos à militância política atual, o capítulo "Ditaduras, marcas e permanências", de Ana Maria Veiga, relaciona aspectos da pesquisa histórica desenvolvida no Laboratório de Estudos de Gênero e História (LEGH), da Universidade Federal de Santa Catarina (UFSC), que estuda as redes de informação e de circulação de discursos e de teorias entre feministas do Brasil e Argentina entre 1970 e 1985, ao "Levante do Bosque" ocorrido recentemente no campus Florianópolis da UFSC. A autora chama a atenção em seu texto/manifesto como os conceitos de gênero e de liberdade devem ser constantemente revisados na sociedade para que a repressão não ocupe seu antigo lugar de poder institucionalizado. As permanências durante os períodos observados pela autora nos fornecem um importante panorama do quanto as discussões teóricas e a militância/ mobilização devem estar aliadas no combate às várias formas de opressão que nos rondam cotidianamente.

O capítulo "Feminismo das Lésbicas", de Marisa Fernandes, é organizado em formato de relato da mesa-redonda na qual apresentou o texto durante o Seminário, bem como de acontecimentos posteriores à apresentação de sua intervenção. O objetivo do texto é demonstrar que o feminismo das lésbicas emerge como pensamento político e se coloca em contraposição a uma vertente heterofeminista. Ao identificar a heterossexualidade como uma ideologia construída e imposta a toda a sociedade humana, oprime todas e todos aquelas/es desviantes à norma. A autora relaciona essa discussão à campanha de setores conservadores que compunha o então cenário político em que tencionava suprimir dos Planos Municipais e Estaduais de Educação os temas e abordagens educacionais que utilizassem: gênero, sexualidade, orientação sexual e identidade de gênero. Para além de viabilizar o canal para discussões que ultrapassam o feminismo hegemônico, o texto traz importantes contribuições para se pensar na manutenção das profundas discriminações e violências baseadas nas diferenças entre os sexos, as sexualidades, contra pessoas negras, pobres, homossexuais, transgêneros, imigrantes, crianças e faixas etárias.

O sexto capítulo que integra esta publicação, "Contribuições críticas do feminismo negro para o empoderamento das mulheres", é de autoria de Cláudia Pons Cardoso e 
propõe uma instigante discussão acerca dos diferentes sujeitos do feminismo e as proposições do feminismo negro para atender as demandas apresentadas pelas mulheres no enfrentamento ao racismo, aos seximos e à heteronormatividade. A autora traz importantes contribuições para pensarmos o feminismo como proposta teórica e política de sujeitos não hegemônicos, pois a incorporação da perspectiva racial tona-se fundamental na medida em que raça reconfigura a forma como as mulheres negras experienciam gênero em muitas sociedades.

No capítulo "Feminismo materialista: uma análise marxista para além do gênero", Mirla Cisne, por meio do estudo da produção teórica do feminismo francês, elabora uma crítica ao termo "gênero" por entender que a sua utilização demanda sempre de uma demarcação teórica e, se comparado aos estudos feministas, adquirem, por vezes, caráter mais "neutro", menos ofensivo (CISNE, 2016, p. 117). De acordo com a autora, o uso da expressão rapports sociaux de sexe (relações sociais de sexo) pela teoria francesa é importante para se pensar as relações sociais entre os sexos por designá-las de maneira mais ampla e numa perspectiva macroestrutural, permitindo vislumbrar relações sociais como antagônicas. A contribuição da teoria social marxista, de acordo com Mirla Cisne, permite ao movimento e aos estudos feministas instrumentalizarem-se para desnaturalizar as relações sexo/gênero e as diversas opressões que estão submetidas as mulheres.

O capítulo que encerra a coleção, "Cartografia políticas da mulher rural no Brasil: rupturas aos modelos instituídos", de autoria de Gema Galgani Silveira Leite Esmeraldo, historiciza a emergência de diversos movimentos de mulheres rurais. A partir disso, a autora aponta para a necessidade de serem tecidas novas formas de existências para a mulheres rurais que as vinculem a outros espaços sociais, políticos e econômicos. Ao longo do texto, Esmeraldo faz referência a importantes conquistas e mobilizações realizadas pelas mulheres rurais ao longo dos anos, a partir dos quais passaram a criar novos significados políticos de autorrepresentação e também produziram um campo de lutas para fazer as conexões e relações da mulher sem-terra às lutas gerais travadas por movimentos de mulheres campesinas.

As reflexões teóricas abordas na coletânea acerca do feminismo como teoria importada do norte global, e que passa a ser pensada conforme as necessidades latino-americanas e brasileiras, bem como as suas especificidades, é o mote do livro. Os textos buscam problematizar, por meio dos feminismos, as imposições/opressões de gênero, de sexo, de orientação sexual, de raça, de localização, de faixa etária, de classe, feitas às mulheres que vivem no sul geográfico do globo. Ao abordar a pluralidade dos debates que as teorias feministas suscitam, a obra, ao aliar a produção acadêmica aos feminismos na atualidade, bem como apresenta-se como notável ferramenta para repensar e superar o estabelecimento de discursos hegemônicos.

\section{Referências}

CISNE, Mirla. Feminismo materialista: uma análise marxista para além do gênero. In: ROCHA, Marcos Antonio Monte (Org.). Feminismos Plurais. Fortaleza: Expressão Gráfica e Editora, 2016, p. 113-132.

FEMENÍAS, María Luisa. Esbozo del feminismo em América Latina. In: ROCHA, Marcos Antonio Monte (Org.). Feminismos Plurais. Fortaleza: Expressão Gráfica e Editora, 2016, p. 27-52.

RAGO, Margeth. Feminismos, artes do viver e invenções da subjetividade. In: ROCHA, Marcos Antonio Monte (Org.). Feminismos Plurais. Fortaleza: Expressão Gráfica e Editora, 2016, p. 9-26.

ROCHA, Marcos Antonio Monte (Org.). Feminismos Plurais. Fortaleza: Expressão Gráfica e Editora, 2016. [Coleção Gênero, Cultura e Mudança]. 
[Recebida em 15/02/2017 e aprovada em 25/06/2017]

Mariane da Silva $\square$ Universidade Federal de Santa Catarina, Florianópolis, SC, Brasil

Mariane da Silva (silva.marianeda@gmail.com) é mestranda do Programa de PósGraduação em História da Universidade Federal de Santa Catarina. Pesquisadora Associada ao Laboratório de Estudo de Gênero e História - LEGH/UFSC. Bacharela e Licenciada em História pela Universidade Federal de Santa Catarina. Atualmente pesquisa a memória dos movimentos de resistência empreendidos por mulheres catarinenses durante a última ditadura militar vivenciada no Brasil.

4 Revista Estudos Feministas, Florianópolis, 26(1): e49018 